\title{
The Importance of Cognitive Styles: Dependence and Field Independence (DIC) in the Memory Process
}

\section{Filomena Ermida da Ponte}

FFCS/ Universidade Católica Portuguesa

Corresponding Author: Filomena Ermida da Ponte, FFCS/ Universidade Católica Portuguesa.

Received date: April 04, 2021; Accepted date: May 17, 2021; Published date: May 24, 2021

Citation: Filomena Ermida da Ponte., (2021) The Importance of Cognitive Styles: Dependence and Field Independence (DIC) in the Memory

Process. J. Neuroscience and Neurological Surgery. 9(2); DOI:10.31579/2578-8868/180

Copyright: () 2021 Filomena Ermida da Ponte, This is an open-access article distributed under the terms of The Creative Commons Attribution License, which permits unrestricted use, distribution, and reproduction in any medium, provided the original author and source are credited

\section{Abstract:}

It is in the framework of a cognition orientation, or theory of information processing, that we seek the theoretical models that can best support us in the analysis of human cognitive functioning, specifically in the tasks of learning and problem solving. Keywords: cognitive psychology; hearing sensitivity

\section{Introduction}

It is in the framework of a cognition orientation, or theory of information processing, that we seek the theoretical models that can best support us in the analysis of human cognitive functioning, specifically in the tasks of learning and problem solving. Indeed, one of the great concerns of teachers, psychologists and educators is to identify and understand the individual differences of students, in particular cognitive differences, due to their important implications for learning, performance and school success of students. It follows, moreover, a growing concern of schools with the individualization of education, assuming this individualisation as one of the guiding principles of educational action, particularly in the context of an "inclusive school". It is particularly on the subject of individual differences in cognition and their impact on learning, that cognitive style dependence-field independence (DIC) achieves its relevance in this research

\section{I- Dependency and Field Independence (DIC) and Memory}

Mnemonic activity is undoubtedly reflected as an essential part in the treatment of information. The encoding, storage and retrieval of information are closely linked aspects of this activity, which control the retention of information and its adaptability for its timely application. It is considered that these processe work in chains and it is not possible to examine the operations of one of them dissociated from the others. The possibility that the cognitive style dependence-independence of the field is related to the individual differences in learning and memory, has been consolidated, in recent times, presumably by the greater emphasis that Cognitive Psychology places on the active role of the individual in the process of acquisition, storage and retrieval of information. This highlight serves as a support for the study of individual differences in learning and memory.

\section{Cognitive Style (DIC) and the coding process}

The codification designation reports us to the set of processes indispensable for the storage of information in memory and that are responsible for the transformation of sensory stimuli into codes or expressive traces and assimilated by memory systems (De Vega, 1998). According to several studies, we are aware of relevant data that suggest the existence of significant differences in the form of coding between different cognitive styles. Frank and Davis (1982) suggest a task of guessing words to pairs of subjects of the same cognitive style or of different styles, according to specific tests. One of the members of the pair would have to guess the words, however the other should provide clues in terms of words that related to the keyword. It was found that the pairs formed by subjects DC required greater support in terms of training and testing. The subjects of cognitive style IC understood more quickly the dynamics of the game. In turn, the mixed pairs revealed an intermediate position between the pairs composed of subjects of the same cognitive style. The authors concluded that CD are characterized by a greater "coding rigidity", since such differences could not be attributed to the nature of the clues used by them. In a later study, Frank (1983) explains these results using the principle of Tulving specificity (Tulving \& Thomson, 1973). This principle argues that words do not have a fixed semantic representation, but that this varies depending on the environmental indices present during the coding process. Thus, the recall of words would depend on the degree to which the situations of codification and recovery intersect. To prove it, he proposed a new task of recall by association with subjects DC and IC, signaled by the test of hidden figures. The task consisted of pairs of words, one of them being polysemic and the other referring to one of the meanings of the first. The author concluded that the principle of specificity would manifest itself more clearly in The Dc, which would explain that in performing tasks with semantically related pairs of words, they show more difficulties to access words that will recover as clues of more distant meaning are offered. IC are characterized by greater flexibility of operation that makes it easier for them to ignore and reject all the "noise" and confusion caused 
by the different lanes that are present in the storage phase. In another study, Durso, Reardon and Jolly (1985), in a different view, present results that reveal, like the previous one, differences in coding between subjects DC and IC. The focus of the work of these authors is the process of distinguishing between memories of external or internal origin of words. They suggested that this process could be conditioned by the greater or lesser i-not $\mathrm{i}$ differentiation that characterizes a subject according to his cognitive style. To confirm this, the authors elaborated a memory test that involved the process of distinction mentioned. This task consisted of the random presentation of complete sentences and incomplete sentences, missing only the last word that the subjects would have to guess. The subjects were then provided with a list of words among which they would have to acknowledge the last of the sentences read earlier and determine whether they were external or internal. The DC revealed greater confusion when mentioning the origin of the recalled words. In order to determine the origin of this confusion on the part of the subjects, the authors tried to ascertain whether this originated in the nature of the traits that characterize these subjects or, simply, in the lower discriminative aptitude on their part. The authors suggested that the richness of external event codes could be lower in field-dependent scans, making it more difficult to distinguish from internal codes, and attribute these results or to differences in the information that is encoded, or to differences in the information used for the recovery of memory trait. Richardson and Turner (2000), in a remarkable explanation, refer to these findings, in the sense that for whom independent field subjects tend to encode as much information as possible before moving on to a new level of information processing. On the contrary, the DC subjects seem to devalue this process by coding only those clues considered more relevant. In the opinion of Sternberg and Grigorenko (1997), it seems that the DC "end" this process without having achieved exhaustive coding. In summary, we can affirm that in the face of the same stimuli, the subjects dependent and field-independent transform them differently into codes or traits assimilated by memory systems. These differences could be minimized by the deliberate and reasonable fluidity of strategies at the time of information coding. Hence, metacognitive abilities constitute a source of indirect influence of cognitive style on the use of strategies.

\section{DIC and the information storage and retrieval process}

The analysis of memory processes would remain incomplete if the circumstances and operations that determine the storage and retrieval of information were not explained. With reference to these processes, differences were also found between dependent and field-independent subjects. One of the first hypotheses of departure was that the lower restructuring ability of the Dc would determine a less organized storage of the information in these subjects. Authors such as Davis and Frank, in 1979 , reviewed different studies that tried to test the hypothesis and found no differences between subjects DC and IC in the total number of words recalled. One of the criticisms made of these studies is that in the task of free recall, the word list provided to the subjects always had an inherent organization. On the contrary, when the recall derived from a task that involved a prior personal organization, yes it was found that the IC subjects obtained better results (Coward \& Lange)

\section{Method}

We describe the sample of children and adolescents participating in our study, as well as the assessment instruments used and the procedures considered either at the time of data collection or in their treatment. In particular, in these procedures we indicate how we distribute students according to their cognitive style: independent, intermediate and field dependent.

\section{1. sample}

The sample of our study consists of two groups of students with different age levels. The first group consists of 98 children aged between 8 and 9 years, students of the 3rd and 4th years of schooling respectively; the second group comprises 95 adolescents aged between 13 and 14 years, students from 7 th and 8th years respectively.

\section{2. instrument}

Adaptation of the Spanish-Complutense Child Verbal Learning Test (TAVECI) (Benedet \& Alexandre, 1998)

The Spanish-Complutense Child Verbal Learning Test (TAVECI) consists of the memorization by the subject of several lists of words read by the evaluator and which, subsequently, will have to evoke or recognize: a learning list (list A), an interference list (list B) and a recognition list. The recall phase is carried out under several conditions: immediately after listening to the words, after having heard and learned a second list, with the help of semantic keys provided by the examiner, after an interval of 20 minutes, and finally employing a recognition list. In each proof of recall, a correct answer will be considered if it appears in the corresponding learning list and appears for the first time in that proof of recall.

\section{Presentation of Results}

All groups (DC and IC) used the serial strategy in both list A, of free recall, as well as in list B, of interference. In the short-term free recall, IC used semantic strategy more frequently compared to DC students, although less than intermediate group students. The same happened in the immediate recall, although here the IC students use more semantic strategy than the DC and intermediate students. Regarding errors, the IC group repeated fewer words (preservation), as well as added fewer words to the evoked list (intrusion) compared to DC students, although more than intermediate students. Finally, in the word recognition list, practically the students of the three groups identified in full the words belonging to the first list presented, even if there is a tendency for a progressive increase in the passage of the DC students intermediates and these for IC students. This brief collection of investigations focuses on a supposed inferiority of field dependents in different memory processe.

In summary, we can conclude that depending on their cognitive style, the subjects seem to serve different sectors of information and encode, store and retrieve the information in different ways. Field-independent people are more effective than field-dependent people in learning and memorization tasks that require selective attention, more elaborate coding processes, restructuring, or those performances in which material that should be retained assuming an overhead for memory.

\section{CONCLUSION}


In our study, applying TAVECI, in the different tests of immediate recall of the list of words presented, there were no significant differences. However, if we analyze the order in which children and adolescents recalled the words, the IC subjects show a greater tendency to group the words recalled, thus reflecting a greater propensity for spontaneous analysis of information at the time of knowledge acquisition, as well as a predisposition to the use of their personal schemes during recovery. Our results are in line with those obtained in studies with children and adolescents (Amador, 1992; Coward \& Lange, 1979) and with adult subjects (Annis, 1979; Balluerka \& González-Tablas, 1996; Frank, 1983; Frank \& Keene, 1993; Kiewra \& Frank, 1986; Rickards et al., 1997).

It is also verified that the IC subjects of the group of children (8-9 years) tend to apply, more assiduously than the DC, a semantic type strategy. This discrepancy reaches expressiveness in the immediate recall of list A. In the group of adolescents (13-14 years), ci use more semantic strategies in the immediate recall of list $\mathrm{A}$ and in the interference list. This differentiation leads us to the type of approach made to information by subjects of different cognitive styles. The DC subjects make a global approach, so it is not surprising that they prefer to deal with the material as a whole (serial strategies). On the contrary, IC employ an analytical approach, which predisposes them to a material search by categorization (semantic strategies) and the imposition of a structure of its own.

The analysis and extraction of orally communicated information content necessarily requires the use of memoristic resources. In this circumstance, there is a superiority on the part of the IC subjects (Bennink, 1982; Bennink \& Spoelstra, 1979; Cochran \& Davis, 1987; Robinson \& Bennink, 1979). This superiority of field independents translates a more diligent use of useful strategies in the management of the attentional space, as well as the realization of inferences about the content of the information that is handled, recoding it and relating it to previous knowledge. We can relate this fact, essentially, to the greater structuring capacity of IC and the plasticity of their information processing style.

Our results also suggest that the two groups of cognitive styles, whether in children or adolescents, improve their performance in short-term and long-term memory tasks, when the experimenter provides them with a categorization of the terms presented. That is, regardless of cognitive style, everyone benefits from foreign aid (Balluerka \& González-Tablas, 1996; Frank \& Keene, 1993; Kiewra \& Frank, 1986; Rickards et al., 1997).

It is interesting to add that, among adolescents, the gain by external aid is clearly higher in DC students in the long-term memory task. According to Ennis (1991), the DC subjects have greater difficulty in abstracting certain relationships acquired in the course of a given learning, making it difficult to achieve them. This fact makes us believe in a predisposition to greater use of strategies by independent field subjects.

Finally, by comfacing the number of correct answers in the recognition test with the words recalled in the TAVECI free recall tests (short- and long-term memory), we verified that the amount of information stored is greater than the amount of information that the subjects evoked. In any of the groups of cognitive styles, there is an improvement in the task of recognizing words, in the face of evocation without help, a situation that occurs with adolescents and, in particular, with children. These results lead us to believe that storage processes are less affected by cognitive style than recovery processes. Thus, the differences observed in memory tasks will be more related to the encoding and recovery processes than to the storage process.

In summary, seeking the convergence of results that are extracted from the characteristics inherent to the test used (TAVECI), more specifically the level of structuring that the test presents, when the material to be assimilated has some type of organization or structure, as is the case of TAVECI, there are no differences in learning between subjects of different cognitive styles.

\section{REFERENCES}

1. Amador, J. A. (1992). Eficacia en la resolución de tareas de aprendizaje en función del estilo cognitivo dependenciaindependencia de campo. Tese de Doutoramento. Barcelona: Universidade de Barcelona.

2. Annis, L. F. (1979). Effect of cognitive style and learning passage organization on study technique effectiveness. Journal of Educational Psychology, 71, 620-626.

3. Balluerka, N., \& González-Tablas, M. M. (1996). Influencia de las instrucciones y de los esquemas en el aprendizaje de textos científicos en función de la dependencia de campo. Psicológica, 17, 143-160.

4. Benedet, M. J., \& Alejandre, M. A. (1998). Test de aprendizaje verbal España-Complutense Infantil (TAVECI). Madrid: TEA Ediciones, S.A. Bennink, 1982;

5. Bennink \& Spoelstra, 1979; Cochran \& Davis, 1987; Robinson \& Bennink, 1979

6. De Vega, M. (1998). Introducción a la psicología cognitiva (9a. ed.). Madrid: Alianza. (Trabalho original publicado em 1984).

7. Ennis, C. D. (1991). Instructional strategies to facilitate the learning of field dependent children. Early Child Development and Care, 67, 95-109.

8. Frank, B. M., \& Davis, J. K. (1982). Effect of field independence match or mismatch on a comunication task. Journal of Educational Psychology, 74, 23-31.

9. Coward, R. T., \& Lange, G. (1979). Recall and recallorganization behaviors of field dependent and field independent children. Psychological Reports, 44, 191-197.

10. Durso, F. T., Reardon, R., \& Jolly, E. J. (1985). Self-nonselfsegregation and reality monitoring. Journal of Personality and Social Psychology, 48, 447-455.

11. Frank, B. M., \& Keene, D. (1993). The effect of learner's field independence, cognitive strategy instruction and inherent wordlist organization on free-recall memory and strategy use. Journal of Experimental Education, 62, 14-25.

12. Grigorenko, E. L., \& Sternberg, R. J. (1995). Thinking styles. Em D. M. Saklofske \& M. Zeidner (Eds.), International Handbook of Personality and Intelligence (pp. 205-229). Nueva York, NY: Plenum Press.

13. Kiewra, K. A., \& Frank, B. M. (1986). Cognitive style: Effects of structure at acquisition and testing. Contemporary Educational Psychology, 11, 253-263.

14. Rickards, J. P., Fajen, B. R., Sullivan, J. F., \& Gillespie, G. (1997). Signaling, notetaking and field dependence- 
independence in text comprehension and recall. Journal of Educational Psychology, 89, 508-517.
15. Tulving, E., \& Thomson, D. M. (1973). Encoding specificity and retrieval processe in episodic memory. Psychological Review, 80, 352-373.
This work is licensed under Creative

Commons Attribution 4.0 License

To Submit Your Article Click Here: Submit Manuscript

DOI: $10.31579 / 2578-8868 / 180$
Ready to submit your research? Choose Auctores and benefit from:

* fast, convenient online submission

* rigorous peer review by experienced research in your field

* rapid publication on acceptance

* authors retain copyrights

* unique DOI for all articles

* immediate, unrestricted online access

At Auctores, research is always in progress.

Learn more www.auctoresonline.org/journals/neuroscience-andneurological-surgery 